\title{
Lower Urinary Tract Symptoms
}

National Cancer Institute

\section{Source}

National Cancer Institute. Lower Urinary Tract Symptoms. NCI Thesaurus. Code C94773.

Symptoms that result from pathologic processes affecting the urinary bladder and/or urethra. They include urinary frequency and urgency, dysuria, nocturia, incomplete voiding, and poor stream during urination. 